\title{
De continuïteit van onzekerheid: middenklassen in de VS
}

\author{
Monique Kremer
}

Cooper, M. (2014). Cut Adrift: Families in Insecure Times. Ewing: University of California Press.de

Een eigen huis, een auto, een baan met benefits, wat spaargeld en kinderen die het verder brengen dan jezelf. Dat zijn de ingrediënten van een typisch Amerikaans middenklassegezin. Anno 1970, wel te verstaan. Want de recente studies over de Amerikaanse middenklasse komen tot een heel ander lijstje middenklasseingrediënten: een torenhoge hypotheekschuld, een baan die onvoldoende loont, hoge kosten voor gezondheidszorg en kinderopvang, en een college degree die niet meer verzekert voor werk. De Amerikaanse droom lijkt veranderd in een uitzichtloos toekomstbeeld waarin onzekerheid troef is.

In haar interessante, veelgeprezen boek Cut Adrift: Families in Insecure Times wijst Marianne Cooper op een aantal oorzaken van de toegenomen bestaansonzekerheid van de middenklasse. De voortdurende privatisering van risico's bijvoorbeeld. Zorg voor kinderen, gezondheidsproblemen en slecht betaald werk komen steeds meer op rekening van het individu. Jacob Hacker schreef hier in 2006 ook al eens een mooi boek over: The Great Risk Shift. Ook is er sprake van een neerwaartse druk op de arbeidsmarkt door globalisering van de economie en skillbiased technological change. De economie brengt daardoor geen goede middenklassebanen meer voort. De lonen stagneren en werk wordt steeds tijdelijker. Ook hier wordt inmiddels door economen veel over geschreven; zie bijvoorbeeld de boeken van Tyler Cowen (zoals Average is over uit 2013).

Maar terwijl veel studies de toenemende onzekerheid in de VS willen verklaren, is de sociologe Cooper iets anders gaan doen. Ze wilde weten hoe middenklassegezinnen de toenemende onzekerheid ervaren. Welke emoties roept het op? En hoe wapenen mensen zich tegen onzekerheid? Cooper stapte binnen bij vijftig middenklassegezinnen in Silicon Valley en leefde - letterlijk - een tijdje met hen samen. Ze nestelde zich op de bank, ging mee naar de voetbalwedstrijd van de oudste zoon, en luisterde naar de vioolles in weer een ander gezin. Al pratend met vrouwen en mannen, samen en afzonderlijk, over geld, werk, relaties en opvoeding bouwde ze een intieme band op zonder haar distantie te verliezen. Daarmee staat Cooper in een intensieve en inzichtgevende sociologische onderzoekstraditie van onder andere Arlie Hochschild (The second shift), die in ons land helaas maar weinig navolging heeft. Zo'n onderzoek kost immers jaren tijd, en van tevoren weet je niet wat en zelfs óf er iets uitkomt.

* $\quad$ Monique Kremer is redactielid van Beleid en Maatschappij. Zij is projectcoördinator van het project 'Middenklasse onder druk?' bij de Wetenschappelijke Raad voor het Regeringsbeleid. 
Want welke inzichten levert al dat voetbal kijken en op de bank zitten precies op? Dat inderdaad bij alle middenklassegezinnen - laag én hoog - sprake is van continue onzekerheid, dus ook als ze een goede baan hebben en een aardig bedrag op de bank. Dat onzekerheid een enorme emotionele aanslag betekent op het leven van mensen, waarbij vooral vrouwen veel van de zorgen op zich nemen. Zij zijn vaak wat Cooper 'the designated worrier' noemt. En dat elk gezin een 'security project' heeft, waarbij ingezet wordt op een 'security strategy'. Vooral deze zekerheidsstrategieën zijn interessant en verschillen per segment van de middenklasse. Cooper onderscheidt er vier: downscaling, upscaling, holding on (op koers blijven) en turning to God, waarbij de eerste twee het meest tot de verbeelding spreken.

Downscaling, de eisen naar beneden bijstellen, komt vooral voor bij de lagere en middensegmenten van de middenklasse, constateert Cooper. Exemplarisch hiervoor is Laura, die de ene financiële tegenslag na de andere krijgt te verduren. Maar ze zegt: 'Geld is niet belangrijk, het allerbelangrijkste is mijn familie.' Downscaling betekent ook: 'je alleen zorgen maken over vandaag, niet over morgen'. Als Laura een duur lot koopt in de loterij, is dat eigenlijk best een logische actie: op die dag heb je tenminste nog een hoopvol gevoel. Downscaling is ook: 'alles mooier verpakken dan het is'. Met slechts enkele dollars op zak voor het avondeten maakt Laura er met haar kinderen in de supermarkt een speelse koopjesjacht van. Cooper schrijft dat zij zich meer zorgen leek te maken over de onzekere situatie bij Laura thuis dan Laura zelf.

Aan de andere kant van het spectrum, bij de hogere middenklasse, ziet Cooper vooral de strategie van upscaling: mensen maken zich veel meer zorgen dan hun financiële situatie doet vermoeden. De hogere middenklasse is veel beter verzekerd door een viertal 'buffers': het hoge inkomen, veelgevraagde kennis en vaardigheden, stabiele work benefits en een sociaal netwerk waardoor je zo weer een baan hebt. De hogere middenklasse maakt zich minder zorgen over haar eigen financiële toekomst, maar des te meer over de toekomst van de kinderen. De strenge vioollessen voor de kinderen van de familie Mah passen daarin. Net als het 'verzekeren van de financiën' zijn de kinderen bij hen ook een 'project'. Ze moeten zo perfect mogelijk worden om te kunnen concurreren met alle andere kinderen in de wereld. Want families die upscalen zijn zich heel erg bewust van de mondiale veranderingen. Omdat de kansen volgens de Mahs straks meer in het Oosten liggen, overwegen ze serieus een verhuizing naar India 'voor de kinderen'. Het is fascinerend om te lezen dat mensen met anderhalf miljoen dollar op de bank zich werkelijk afvragen of het wel genoeg is. Niemand voelt zich blijkbaar echt rijk. Niemand lijkt ooit geld genoeg te hebben om zich zeker te voelen van zijn zaak.

Deze copingsstrategieën laten een mooi beeld zien van de worsteling van gezinnen in Silicon Valley in tijden van onzekerheid. Maar zijn de analyse en het theoretisch kader ook bruikbaar om de 'zekerheidsstrategieën' in de Nederlandse context te onderzoeken en begrijpen? Het boek kan immers gelezen worden als één grote lofzang op onze sociale zekerheid, onze collectieve arbeidsovereenkomsten, onze betaalbare scholen en ziekenhuizen. Tegelijkertijd is er ook in Nederland sprake van toegenomen onzekerheid, vooral op de arbeidsmarkt: een kwart van de werkenden heeft geen vast arbeidscontract. Middenklassegezinnen in Neder- 
land hebben nauwelijks vermogen op de bank, terwijl ook in ons land een deel van de risico's wordt geprivatiseerd - denk aan het hoger onderwijs en de zorg. En ook in Nederland maakt een groot deel van de mensen zich zorgen over de toekomst van hun kinderen (SCP, 2014).

Toch komen veel van de beschrijvingen in het boek over als typisch Amerikaans. Het is bijvoorbeeld opvallend dat niemand in het boek negatieve emoties toont. Als de rekeningen binnenstromen of het zoveelste ontslag boven het hoofd hangt, zien we zelfs maar weinig emoties. Niemand is boos, teleurgesteld of onberekenbaar. Niemand reageert zich af, bijvoorbeeld op manlief of de kinderen, terwijl dat toch zichtbaar zou kunnen zijn als je zo vaak bij mensen thuis komt. Geen van de geïnterviewden lijkt zich ook te keren tegen de tekortschietende overheid, de superrijken, of 'globalisering'. Ook zou je verwachten dat mensen in tijden van onzekerheid gestrest zijn en daardoor lethargisch, zoals blijkt uit andere recente studies. En waarom laat niemand in Cut Adrift alles uit zijn handen vallen?

Misschien nekt zich hier de opgeruimde, positieve psychologie waartoe Amerikanen verplicht lijken te zijn, maar misschien is er iets anders aan de hand. Cooper geeft vermoedelijk te weinig inzicht in contrasterende geluiden en tegenverhalen: in de lagere middenklasse zijn heus niet alleen engelen als Laura te vinden die elke financiële tegenslag omzetten in een positieve uitdaging. Meer negatieve emoties laten zien had wellicht een zeker empirisch onbehagen bij de lezer kunnen wegnemen. Maar misschien zorgt het ontbreken van woede, angst en frustratie in de beschrijving ook wel voor een zeker theoretisch onbehagen. Cooper wil bijdragen aan een theorie van emoties en inzicht geven in de stratificatie van emoties. Maar wat we eigenlijk zien is dat emoties helemaal niet leidend zijn voor het gedrag van de personen in kwestie. Als ze er al zijn, worden ze omgezet in een praktische copingsstrategie. Haar emotietheorie is dus eigenlijk wat aan de schrale kant. Want Cooper laat vooral zien hoe praktisch en probleemoplossend mensen zijn.

Deze kanttekeningen laten onverlet dat het boek zeker de moeite waard is. Het is mooi geschreven en biedt een intieme blik op middenklassegezinnen in de VS. Het wachten is nu op een Nederlandse Marianne Cooper, want een - zij het mildere - vorm van onzekerheid is ook bij ons aan de orde. Wie neemt de tijd om ook in ons land te onderzoeken wat de toenemende onzekerheid precies betekent voor middenklassegezinnen?

\section{Literatuur}

Cooper, M. (2014). Cut Adrift. Families in Insecure Times. University of Calefornia Press. Cowen, T. (2013). Average is over. Powering America beyond the Age of the Great Stagnation. New York: Penguin.

Hacker, J.S. (2006). The Great Risk Shift. The Assault on American Jobs, Families, health care, and Retirement And How You Can Fight Back. Oxford: Oxford University Press.

SCP (2014). Verschil in Nederland. Sociaal en Cultureel Rapport 2014. Den Haag: SCP. 